\title{
ONTOLOGIAS DO VER NA ATUALIDADE: \\ QUE PODE UM OLHAR PRECÁRIO
}

\author{
Kleber Jean Matos Lopes $\star$ \\ Elen Naiara Batista Madeiro $\star \star$ \\ Jameson Thiago Farias Silva $\star \star \star$
}

\begin{abstract}
RESUMO
Esse trabalho problematiza os modos de olhar na atualidade e analisa politicas de constituição do ver através das noções de olhar precário e olhar total; dispostos como lógicas de produção desentidos. Os modos dever são apresentados genealogicamente e relacionados aos modos de produção e expressão do pensamento, às biopolíticas na atualidade e ao fazer do cinema contemporâneo. Discute duas experiências de cinema através dos filmes $O$ escafandro e a borboleta e A professora de piano, para pensar movimentos de produção da individualidade ou modos de subjetivação que possibilitam exercícios de autonomia e fabricação de coletivos.
\end{abstract}

Palavras-chave: politicas da imagem; modos de subjetivação; cinema; olhar precário.

\section{ONTOlOGies OF SIGHT IN PRESENT DAYS:}

\section{WHAT CAN A PRECARIOUS VIEW}

\begin{abstract}
This paper discusses the ways of view in present days and analyzes policies constitution of the look, through the notions of the precarious view and total look; disposed as logical for the production of the senses. The ways of view are genealogical presented and related to the modes of production and expression of thought, to the biopolitical in the present time and to the make of the contemporary cinema. Discusses two cinema experiences through the movies Le scaphandre et le papillon and La pianist, to think movements of individuality production or modes of subjectivity that allow exercises of autonomy and fabrication of collective.
\end{abstract}

Keywords: politics of image; modes of subjectivity; cinema; precarious view

^ Professor Adjunto do Departamento de Psicologia da Universidade Federal de Sergipe. Professor permanente do Programa de Pós-graduação em psicologia Social da UFS. Endereço: Cidade Universitária Professor José Aloísio de Campos. São Cristóvão - Sergipe. CEP: 49.100-000 E-mail:klebermatos@uol.com.br

$\star \star$ Graduada em Psicologia da Universidade Federal de Sergipe. Pesquisadora e bolsista do PIBIC 2009/2010.

E-mail: elen.naiara@yahoo.com.br

$\star \star \star$ Estudante de Psicologia na Universidade Federal de Sergipe. Pesquisador e bolsista do PIBIC 2009/2010.

E-mail: anciao_eldar@hotmail.com 


\section{INTRODUÇÃO}

Máquinas de ver multiplicam seus usos e funções acionando modos de vida na contemporaneidade. A sensação de registro das ações humanas parece já ter sido incorporada ao movimento das pessoas nas grandes cidades, tanto em ambientes privados como em situações de convívio público. Câmeras digitalizam os acontecimentos e se fazem testemunhas privilegiadas daquilo que difere e daquilo que se repete na produção do dia-a-dia na vida das pessoas. Já há um tempo, pais podem verificar a vida dos filhos em creches e escolas, como também em casa através de um terminal de computador ligado a câmeras ordenadas nesses lugares. Grandes ou pequenos estabelecimentos comerciais fazem o mesmo em relação a seus funcionários e clientes. Terminais " 24 horas" de bancos fazem a captura da imagem dos seus usuários. Ônibus de transporte coletivo também mantém um registro eletrônico do que acontece em seu interior. A idéia de materialização da máxima vigilância através desses modos de registro digital de imagens se efetiva em processos de decisão variados, marcados por interesses diversos, mas esses processos guardam em comum uma política preventiva e de checagem, que lhes configuram como um dispositivo otimizado do controle do que se fez, para assim, sendo necessário, intervir no que se passou ou naquilo que se está a fazer.

O controle do presente é o sentido fundamental dessa política imagética, que mantém dispositivos de vigilância, que, se não garantem a manutenção de práticas regulares para os comportamentos, denunciam e ocasionalmente punem os desvios do que está estabelecido como conduta. Olhares das câmeras espalhados pelo recantos do planeta convergem para uma política do ver que atua na gerência das populações, tomando assim uma massa por conjunto, ativando também um modo de experiência individual de resguardo. Um modo de o sujeito cuidar de si, para que sua distinção no conjunto ao qual pertença esteja pré-estabelecida nos limites de possibilidade do mesmo. Daí o olhar absoluto e objetivo das câmeras para o vivo se alia a cada olhar humano, num movimento em busca de dizer de si por aquilo que conserva o ser vivo, imerso em coisas que lhe são próprias, mas sempre disposto numa ordem biopolítica (FOUCAULT, 1999). O olhar do controle apresenta as suas credenciais e ensina como se deve olhar pra si, ver o que está dado e daí regular os próprios movimentos. Tomar decisões.

Inquietante, entretanto, notar como essa biopolítica do ver e de produção das imagens e seus consequentes modos de consumo instauram um ideal de nitidez a ser perseguido. O olhar deixa de ser tomado como algo que possa ser pensado, passando a funcionar como algo a ser medido. Uma materialização se objetiva na cena e no que ela contém enquanto imagem, como se a cena fosse apenas o que se movimenta naquilo que a câmera flagra, como se não houvesse vida no antes ou no pós-foco. Aquilo que destoa é subtraído do plano de verificação e fica à margem, sendo enquadrado em clichês como equivoco, erro, achismo ou algo pessoal. O olhar objetivo e absoluto condena o que se mostra precário e parcial no que tange aos modos de ver num mundo que investe no controle, como política de regulação para as experiências do viver. 
Entretanto, os avanços tecnológicos de viés eletrônico, aliados aos modos de gestão dos vivos, são instituições recentes na historiografia do humano. Remontam há pouco mais do que dois séculos, daí, talvez nesse momento, onde evoluem políticas para extinguir o precário e o parcial nos modos de ver, alguma importância exista em problematizar o que seriam os modos de olhar, quando não tinham a seu serviço os dispositivos imagéticos da atualidade. Pensar a biopolítica dos modos de ver contemporâneos aponta para discussões que possibilitem a não naturalização do vivo enquanto espécie humana e é para isso que essas linhas se voltam buscando articular a uma história da visão que percorra processos da inserção das biopolíticas nos modos de viver, problematizando-os através da análise dos filmes A Professora de Piano e O Escafandro e a Borboleta.

\section{Pensando a CONDIÇÃo do OlHAR PReCÁRIO EM TEMPOS BIOPOlíticos}

Ao olhar total das biopolíticas do ver contrapõe-se o olhar parcial, como uma força capaz de participar dos modos de produção de sentido. Esse olhar parcial designado aqui por olhar precário trabalha no registro da insuficiência, o que lhe carrega em forças para possibilidades de encontro. Qualquer olhar precário possui essa sina de não se bastar e com ela pode encontrar aquilo que seja capaz de potencializar ainda mais a parcialidade do seu alcance visual. O incremento da sua insuficiência lhe possibilita a invenção das imagens que mira e não apenas uma decodificação. Aponta-se assim para uma condição dos modos de ver e lidar com o que se faz ou se quer verdadeiro.

Um olhar insuficiente e ciente de sua condição é um olhar que busca um outro para fazer em par um encontro e produzir algum sentido. Ele observa como quem não sabe, mas quer saber, não sobre o seu ponto de vista, já que é precário, mas naquilo que se faz nesse encontro com um outro. Ele não é tragado pelo quadro que se compõe a sua frente e também não resume esse quadro à sua percepção. A insuficiência que aprimorou traduz uma habilidade em adentrar nas margens dos sentidos imediatos, de deixar a primeira cena, sair da cena.

O olhar precário é quase nada sem parcerias e encontros. Sua política é estar quase sempre em desencontro, mas ativo em querer encontrar algo ou alguém. Trata-se de uma filosofia dos modos de percepção e, em se tratando de filosofia, imagens da produção nietzschiana em tempos de semi-árido no pensamento são como nuvens acinzentadas no céu, que permitem imaginar o cheiro da terra molhada, na chuva que se avizinha.

Diz Nietzsche (2000, p. 270): "Por mais que o homem se estenda em seu conhecimento, por mais objetivo que pareça a si mesmo: enfim nada tirará disso, a não ser sua própria biografia". O filósofo desencana o homem do si-mesmo, alerta para os riscos do olhar absoluto, objetivo, genérico e totalizante. Nesse breve e intenso fragmento, acentua a necessidade do não pertencimento das coisas, das experiências, dos saberes a um plano exclusivo de codificação. É como se dissesse que ver de menos pode ser mais interessante que ver demais. Como se gritasse que a insuficiência do ver não permite ao ser se bastar. 
Em A Esperança de Pandora, Bruno Latour (2001) apresenta movimentos que problematizam a produção do saber, que se estendem da denúncia ao acordo moderno para a produção da verdade na história do ocidente até a possibilidade de fabricação do conhecimento por coletivos, através do que ele toma por uma relação em par, composta por humanos e não-humanos. Uma construção híbrida, impura e parcial é o conhecimento para Latour. Um produto-saber disposto a novos encontros. Para ele, o ato de produzir saber não está no mérito do sujeito conhecedor, nem na imposição à realidade da conhecida. A produção de saber é como um organismo vivo que conta com um sistema circulatório labiríntico, onde em suas veias e artérias circulam humanos e não-humanos que alimentam esse organismo com a energia que é produzida nas colisões de uns com outros. O olhar que corre nas vias desse coletivo vivo somente produz a partir dos encontros, portanto é precário ou insuficiente em relação ao pensar de Latour (2001).

Em Gilles Deleuze, a precariedade do olhar ressoa como condição para uma política por intercessores. O sentido nesse texto valoriza antes a interferência que a possibilidade de um registro insípido, incolor e inodoro de alguma plausibilidade. Deleuze (1992) mira a interferência como condição para o ato de pensar, um trabalho para a criação. Reverbera em seu dizer a necessidade de fabular como um movimento capaz de inventar modos de estar no mundo.

Pegar as pessoas em flagrante delito de fabular é captar o movimento de constituição de um povo. Os povos não preexistem. De certa maneira, o povo é o que falta, como dizia Paul Klee. Será que existia um povo palestino? Israel diz que não. Sem dúvida existia um, mas isso não é o essencial. Pois, a partir do momento em que os palestinos são expulsos de seu território, na medida em que resistem, eles entram num processo de constituição de um povo. Isso corresponde exatamente ao que Perrault chama de flagrante delito de fabular. Não existe povo que não se constitua assim. Então, às ficções pré-estabelecidas que remetem sempre ao discurso do colonizador, trata-se de opor o discurso de minoria, que se faz com os intercessores (DELEUZE, 1992, p. 157).

É bela a imagem deleuziana do modo de fabular e do modo de se fazer minoria. São dois processos aí envolvidos. Fabular para o mundo e para si ao mesmo tempo e nesse tempo encontrar a ressonância que permite a invenção, que incorpora a diferença que a fábula traz e com ela constitui uma realidade partilhada, uma coletividade. O olhar precário potencialmente ativa a condição de encontro e partilha. O olhar precário é força que intui a fabulação e nessa atividade opõe-se aos processos de captura e colonização. Desse modo, o olhar precário é um olhar intuitivo e parcial. Daí sua necessidade de fazer em par. Com Deleuze, o olhar aponta para um modo de precarização criativo, fabulante e parceiro nos modos de composição do mundo. Um olhar que se opõe aos pré-estabelecidos e às formas colonizadoras. 
A idéia de colonização em geral supõe uma hierarquia entre colonizador e colonizado, buscando justificar o próprio processo de colonização. O colonizado é tomado por inferior, menor, insuficiente e incapaz. O colonizador como aquele que instituí uma gramática particular para instaurar a verdade e a metodologia de seu uso. Essa reflexão em torno da noção de olhar precário e de problematização das biopolíticas do ver recusa essa dicotomia como referência para pensar essas questões. Entretanto a toma como uma modo de condução das experiências da vida e, ante ela, assume-se como uma contra-conduta (FOUCAULT, 2008). Na política do encontro há que se privilegiar a novidade, a produção criativa que trabalha na fabricação de outros modos de estar vivendo. Assim não é o olhar precário um produto da resistência a um olhar totalizador, posto que sua genealogia apresenta uma duração mais extensa. Novamente Nietzsche (1976, p. 78):

A má consciência é para mim o estado mórbido em que devia ter caído o homem quando sofreu a transformação mais radical que nunca houve, a que ele se produziu quando se viu acorrentado à argola da sociedade e da paz. À maneira dos peixes obrigados a adaptarem-se a viver em terra, esses semianimais, acostumados à vida selvagem, à guerra, às correrias e aventuras, viram-se obrigados de repente a renunciar a todos os seus nobres instintos.

A fabulação nietzschiana anuncia um mundo onde pairava a precarização do olhar e a vida se fazia num modo de viver aguerrido, apaixonado e incerto. Daí segue outra fábula, essa que supõe em um dia qualquer desse tempo remoto, um olho se dispôs sobre outro. Isso sem saber o que estava fazendo, já que o olhar precário não sabe bem o que faz ao certo. Deu-se aí, depois dessa disposição um efeito qualquer que envolveu o olhar numa busca de repetição, que lhe conduziu a um processo de aprimoramento e se desdobrou num modo de relação consigo e com o mundo onde a guerra, a paixão e a incerteza se dispuseram enquanto entraves e não mais modos de vida.

Esse efeito, absolutamente não datável, estabelece um percurso visual. A parcialidade se traduz por limitação. É uma outra política sendo acionada. Não mais a da fabulação intercessora, parcial e criativa. Agora o parcial demanda instrumentos para se afirmar sobre os parciais desinstrumentalizados. A guerra continuada por outros modos, como diria Foucault (1999), quando o que está em luta é a defesa de bandeiras.

O que se precisava dizer então é que antes da emergência de uma vida instrumental, havia a vida, em qualquer tempo. É essa a condição. E a vida não se bastando, se qualifica e desses modos de qualificação, se expande, se reifica, se contraria, se inventa. Isso é uma outra história. Nesse momento, a história é anterior. É construir uma imagem que permita em texto sustentar a idéia de que a vida normativa é quem resiste ao olhar precário, em estratégias de extermínio de uma política autopoiética (MATURANA; VARELA, 1995), que esse difundia em seu fazer. É desse modo que emerge uma outra proposição do olhar total, que seria um olhar que busca através de processos de instrumentalização do seu 
foco, ultrapassar a condição de precariedade dos campos imagéticos. Um olhar que busca se dispor como o olhar, subvertendo a sua singularidade perceptiva por um modo de identificação persecutório. Um olhar com razões que buscam se estabelecer antes da experiência do ver, para que o ver seja aqui o que se permite enxergar, aquilo que vai se dar às vistas. Jogos do verdadeiro.

Ressoa nesse modo de encaminhar a questão o pensamento do dromólogo Paul Virilio, como também do filósofo Michel Foucault. Em Virilio (2002a), na sua discussão sobre a genealogia do olhar, evidenciam-se os efeitos da vida instantânea sobre os antigos modos de assimilação, retenção e recuperação das mensagens mentais que, para esses, foram devastadores. Sobre o olhar se envolveram procedimentos de mecanização, processos que não ocorrem sem uma considerável perda de autonomia. Ou seja, o que vem se afirmando e está cada vez mais forte no campo da política do olhar é o que Virilio chama de Máquina de Visão, resultado de um processo que teve o olho humano como objeto de cobiça, mas que para alcançar o desejado, primeiro retirou o que havia de humano no olhar, no caso a sua precariedade e vontade de encontro, para depois transpor esse novo olhar desumanizado para a máquina, que nesse ponto, também já desumanizada, efetiva sua sobreposição ao olhar humano.

Uma história que acentua um investimento na objetivação que o desenvolvimento tecnológico enseja e, mais que isso, uma política de sobreposição desse desenvolvimento nos processos de subjetivação modernos e contemporâneos. Nesse sentido, a discussão proposta por Paul Virilio encontra-se aqui com a análise foucaultiana sobre a produção e expansão dos modos da experiência disciplinar e das biopolíticas que, ao longo dos últimos três séculos, marcam modos de ser e estar no mundo. Michel Foucault (1995) primeiro reconhece na genealogia da vida moderna uma maneira de exercício de força marcado por minúcias que produziram um modo-indivíduo capaz de adequação às normas e a um projeto de vida liberal que estava em ascensão pela Europa do século XIX. Um ser docilizado que é absorvido pela cronologia que organiza os espaços de produção e convivência, submetido a um registro permanente de suas ações, que podem se dar por uma hierarquia circunstancial, mas que se efetivam principalmente através de um modo de ver a si-mesmo, todo o tempo. Um olhar da interioridade que está sendo edificado; um olhar panóptico. A esses procedimentos, Michel Foucault denominou poder disciplinar.

Importante apontar para um paradoxo que se estabelece com uma idéia de totalidade que guarda o registro de uma singularidade privada, aqui tomada por individualidade. $\mathrm{O}$ grande olhar, o pan-óptico, alimenta-se com as diligências que se voltam para um si-ensimesmado. É preciso saber desse si que se configura numa forma-eu, dos seus limites e medos, das suas capacidades e competências que configuram o desempenho das experimentações cotidianas. Em Franz Kafka (1986), o personagem Gregor Sansa é a denúncia desse modo de configuração do si. Como um eu-sujeito-moderno, Sansa seria um modo de si que não conseguiu ensimesmar-se. Um sujeito que, posto nas malhas da individualização, desperta para o que construía, já não podendo atender as demandas que se impusera em suas conexões com o mundo. Do drama burguês inaugura uma breve tragédia 
quando sua vida não mais comporta o seu corpo. A metamorfose se dava no tempo de Sansa, mas o tempo da conveniência panóptica resistia aos seus horizontes. Vê assim sumir os fragmentos que compunham uma verdade que supunha possuir: perde o emprego, se vê abandonado pela família, desencontra-se com a vida cotidiana de sua época, pois os modos formais daquela circunstância social e as instâncias morais vigentes não o acolhem.

O personagem Gregor Sansa vê sumir seu chão e esse parece ser um alerta da intempestiva literatura de Franz Kafka; uma denúncia de que uma hora ou outra o chão pode sumir para as criaturas que se fazem humanas e cultuam o próprio sentimento como modo de ocupação afetiva. Após a morte de Gregor Sansa, seus pais e irmã, por Kafka, encaminham assim seus destinos:

Depois os três deixaram juntos o apartamento, coisa que não faziam há meses e foram de bonde elétrico para o ar livre do subúrbio da cidade. $\mathrm{O}$ bonde em que ficaram sentados sozinhos estava totalmente iluminado pelo sol cálido. Recostados com conforto nos seus bancos, conversaram sobre as perspectivas do futuro, descobrindo que, examinadas de perto, elas não eram de modo algum más, pois os três tinham empregos muito vantajosos e particularmente promissores - sobre os quais, na verdade, nunca tinham feito perguntas pormenorizadas um ao outro. É claro que a grande melhora imediata da situação viria, facilmente, da mudança de casa; eles agora queriam um apartamento menor e mais barato, mas mais bem situado e sobretudo mais prático do que o atual, que tinha sido escolhido por Gregor (KAFKA, 1986, p. 87).

Em A metamorfose de Franz Kafka (1986), a família de Sansa toma nas mãos o seu destino após a morte daquele que fora seu provedor durante muito tempo. Essa decisão, carregada de boas perspectivas, efetiva o desapego com a condição de memória implicada com o moribundo-Gregor ou mesmo o provedor-Gregor. Não seria absurdo apontar aí uma decisão disciplinar - panóptica - de quem necessita e quer outro modo de relação consigo e com o mundo, nessa sequência, para garantir acesso às boas novidades da vida moderna, que se anunciavam, já no começo do século XX.

Importante estabelecer a relação dessa condição disciplinar que demanda um olhar que se debruça sobre o si-mesmo e desse modo efetua uma possibilidade de aprimoramento do olhar precário com outro processo histórico que vai produzir um olhar abrangente e totalizador dos modos existenciais, ao longo do que se toma por modernidade: o olhar do biopoder (FOUCAULT, 1999). Ao mesmo tempo em que se desenvolvia essa anátomo-política para os corpos enquanto indivíduos, entendida por constituição da economia disciplinar, Foucault vê funcionar, na mesma Europa, modos de tomar esses corpos por conjunto, no sentido de dispô-los e organiza-los num território, ativando através desses procedimentos meios de garantias para a vida da espécie. Toma-os assim como um corpo-conjunto denominado população. Essa conversa aparece em várias cenas 
da vida europeia desde o século XVII, mas a sua emergência como política pública genérica se faz primeiro no reordenamento do estado alemão. Ali Michel Foucault (1993) vê surgir procedimentos biopolíticos, como a emergência de uma medicina social, que funciona como um dispositivo que marca a produção de registros e normas voltados para a preservação do biológico como foco inicial da formalização dos modos de conduta.

Decisões sobre processos regulamentares e de normalizações das condutas são atributos do Estado e se vê nesse momento o cruzamento da dimensão panóptica-individual das existências com os processos de adequação das mesmas aos modos de racionalização governamental, que incidiam nas experiências que eram atravessadas por questões sanitárias, como a higiene, a natalidade, a longevidade, etc. Inventa-se o tempo das biopolíticas, marcado inicialmente por essa generalização que se inicia pela configuração moderna do Estado alemão, mas que daí estabelece um percurso de especialização do seu fazer, que vai se incorporar aos modos de gestão dos espaços urbanos, para em seguida dar conta das condições do trabalho nas fábricas, ocupando progressivamente os processos de expressão da vida, desde uma dimensão geral até uma experiência marcada por particularidades, mantendo sempre a lógica de produzir o viver, deixando que morram aqueles que não se conformarem às biopolíticas (FOUCAULT, 1993, 1999).

Efeitos da política do fazer viver e deixar que morra propaga-se pelo planeta ao longo do século XX, e apontam para investimentos intensivos e massivos sobre a produção de olhares marcados por uma potência para o absoluto. No ocaso desse século, Gilles Deleuze (1992) anuncia uma nova inscrição subjetiva que emergia nas experiências do viver. Em texto breve e pretensioso diz Deleuze que, enquanto sociedade, já não temos mais a marca da arquitetura disciplinar. Denuncia a falência do espaço que se organizou para a administração dos vivos. É disso que ele fala. Não fala do fim da disciplina ou mesmo dos modos da extinção da lógica de subjetivação disciplinar. Fala que uma configuração que se quis morada dessa lógica ruiu, apontando para o término do espaço demarcado para atividades específicas que ordenavam um modo de fazer também particular. Deleuze diz do fim das fronteiras e do fim do gestor unitário como vetor diferenciado que incide sobre os modos de vida. Anuncia pelos ditos e não-ditos daquele texto, que ao corpo-individual cabe agora outras modalidades de efetivação para que sobrevivam a essa nova disposição biopolítica, que ele batiza por sociedade de controle. O racismo moderno, fundado por concepções biológicas para o humano (FOUCAULT, 1999), atinge assim seu almejado platô de ser efetivo em cada corpo disposto às flutuações do modo de vida, marcado por processos informacionais e de consumo incondicional. Uma ordem flutuante experimenta o capitalismo já desmanchado no ar, mas ainda capitalismo. Uma nova ordem mundial que expurga da vida as experiências do fora, da diferença, da parcialidade e do intempestivo. Eis a sociedade mundial de controle.

A marcação dessa intensidade se faz pela busca da destituição de qualquer fora possível (HARDT, 2000; NEVES, 2004). Valores e experiências quaisquer devem tender à incorporação por essa nova ordenação, onde o eu é substancializado por algo que já traz uma marca de significação. Esse mundo sem fora, 
devorador das potencias para o diferente, almeja sempre a garantia do seu significado, agindo como se o tempo presente pudesse ser reduzido a um conjunto de sensações individuais, passíveis de alguma representação, mesmo que imprecisa e efêmera. Como se cada instante fosse por si a sua totalidade.

É em meio a essa conversa que nos cabe a problematização entre as forças dos instituídos-instituintes dos biopoderes contemporâneos que pontuam a condição de uma totalidade finita e arbitrária para as experiências do ver, o que definimos como olhar total, e uma outra condição que prima pela autonomia da imprecisão do ver e que aponta para produção de alternativas ao que está dado, que tomamos por olhar precário. Como campo para essa problematização decidimos pelo cinema e as experiências estético-políticas que apertam o coração e aquelas que retiram o chão.

\section{DOIS FILMES, QUANTOS MUNDOS?}

Ao pensar a aceleração que se impõe aos processos perceptivos, Paul Virilio (2002b[1996]) revela formas de poder que atuam cada vez mais rápidas e que não necessitam de espaços fechados para seu exercício. Ele faz reflexões sobre uma crise instalada nos modos de representação analisando o que chama de logística da percepção. Essa logística desconsidera antigos modos de produção de imagens mentais em nome da instantaneidade e efemeridade perceptiva que evolui na construção de imagens mentais. A consolidação de imagens à moda antiga estava diretamente ligada aos usos que se fazia do aparelho óptico fisiológico. De outro modo, com as tecnologias informacionais comprimindo as dimensões do universo, produz-se uma potência disposta ao olhar que não mais lhe pertence. No caso, ver além do seu alcance. Virilio (2002a) qualifica essa relação como um processo que subjuga a aptidão fisiológica do olhar, o que impõe uma negativização da sua precariedade, tomando-o agora como obsoleto, falível e que demanda próteses que lhe ampliem a dimensão visual, como uso de lentes macro, microscópica, telescópica e em seguida imagens produzidas por ressonâncias eletromagnéticas. Essa relação é marcada por uma politica que visa o controle, já que os artefatos tecnológicos não estão disponíveis às massas, no que tange seu consumo ampliado e público, muito menos o conhecimento que lhe garante produção e funcionamento. Uma relação de captura violenta, marcada por uma dinâmica que pontua o que deve ser e o que não deve ser importante, válido e verdadeiro.

Daí, chegamos ao cinema como um campo de discussão dessas condições de exercício do olhar precário. $\mathrm{O}$ cinema como máquina que reforça ou acusa essa condição de controle. $\mathrm{O}$ cinema como um entretenimento que ativa uma experiência sensório-motora ou o cinema que se propõe uma dimensão estéticopolítica que acione possibilidades de diferença em busca de outra dimensão temporal que não o aqui-agora, demandando assim a criação de novas realidades.

Diz Deleuze (1992, p. 223) que "[...] é fácil fazer corresponder a cada sociedade certos tipos de máquina, não porque as máquinas sejam determinantes, mas porque elas exprimem as formas sociais capazes de lhe darem nascimento e utilizá-las". As máquinas funcionam como dispositivos que produzem e agregam 
às experiências que realizam seus esforços por manutenção de um certo estado de coisas ou por uma postura contra essa política, em busca de uma outra dimensão estética, para que suas ações desencaminhem o que está posto e realizem um outro evento (CONDE, 2005).

Esse jogo que busca a produção de permanências ou de descaminhos, aqui nomearemos de experiências que apertam o coração, ou que retiram o chão daqueles que com ela compõem. As forças que trabalham por uma captura sentimental, o fazem atuando como máquinas de repetição. A sua linguagem qualifica-se pela capacidade de síntese que uma experiência estética possa produzir. Daí o cinemaque-aperta-o-coração assume uma dimensão industrial no seu fazer, fabricando experiências áudio-visuais voltadas para demandas sensório-motoras (DELEUZE, 1992 apud VASCONCELLOS, 2006), que funcionam ao mesmo tempo de modo genérico, quando tomando seu público por conjunto, e também particular, quando viabiliza uma sensação de intimidade com o indivíduo, que se permitira uma absorção sentimental com aquilo que passa na tela.

Esse jogo que generaliza e particulariza a relação do humano com um certo modo de produção e disposição de imagens áudio-visuais funciona como um dispositivo biopolítico produtor de subjetividades normalizadas, marcadas por processos de consumo que atendem a uma condição imediata dos sujeitos. Há uma emoção a ser perseguida e o enredo da película o faz através de situações que moralizam o sentido desse modo de cinema, pois seu alvo se reflete no que se toma pela interioridade de cada sujeito que o assiste. É como se esse cinema estivesse a comprovar essa condição de interioridade, que demanda cuidados, aprimoramento e contra-partida.

O outro modo de cinema que tratamos aqui é o cinema-que-retira-o-chão. Esse cinema atua noutra dimensão estético-política, se posto em comparação com o cinema-que-aperta-o-coração. Retirar o chão é como que demandar desterritorializações (GUATTARI; ROLNIK, 1996). É denunciar uma zona de conforto existencial e anunciar um convite a outras possíveis territorializações. É investir num tempo não disposto no instante, mas marcado por uma política do futuro do pretérito (CONDE, 2005), onde o que estamos a fazer de nós é uma condição de pensamento que inventa o vivo na vida. Marcas de um sujeito que rompe com a condição de um si-ensimesmado e inaugura uma outra possibilidade estética.

Para uma única pessoa, a realidade do mundo seria sem verossimilhança. Porém, para duas pessoas, ela se torna verossímil. Com efeito, a outra pessoa é uma ilusão de nós, totalmente nossa "vontade", totalmente nossa "representação": e nós somos nela. Todavia, como sabemos que ela necessariamente se engana a nosso respeito e que somos uma realidade apesar do fantasma que ela faz de nós em sua cabeça, concluímos que ela também é uma realidade, apesar da ilusão que temos a seu respeito: em poucas palavras, que há realidades fora de nós. (NIETZSCHE, 2005, p. 83) 
Essa possibilidade de realização fora da condição em que se encontra o sujeito, mesmo como efeito da ação de um olhar que se engana, de um olhar precário, inventa um modo de enunciação coletivo, onde um vai se dizendo no outro e assim em sucessão. Produz uma ética esse cinema que retira o chão, quando da sua roteirização e produção, carregando essa marca para a experiência áudio-visual que enseja. Ele é o encontro num espaço que se dá fora da tela, fora do si-ensimesmado e fora, ainda, do espaço material e objetivo desse encontro, no caso o espaço de projeção. A realização do fora se dá num tempo-espaço a ser inventado.

Para exemplificar esses dois modos de cinema, trazemos aqui os filmes $A$ Professora de Piano (HANEKE, 2001) e O Escafandro e a Borboleta (SCHNABEL, 2007) que funcionam nos dois registros da discussão política, ética e estética que apresentamos. Em O Escafandro e a Borboleta temos a história de superação de um acidente vascular cerebral em Jean-Dominique Bauby, que o deixa imobilizado, tendo apenas o olho esquerdo sob seu controle. Diagnosticado como portador da "Síndrome do encarceramento", Jean-Dominique tem preservada as funções do cérebro, estando impossibilitado entretanto que os seus comandos cheguem às partes do corpo. Vê, ouve, raciocina, emociona-se e compreende o mundo da mesma forma que antes, mas tem agora apenas o olho esquerdo para fazer contato com o mundo.

Dominique se encontra então num hospital, que serve de cenário principal para o filme, e vê confluírem para sua pessoa esforços clínicos da medicina, fonoaudiologia, fisioterapia, enfermagem dentre outros, como um propósito alimentado por uma esperança de recuperação. Dominique, entretanto, se mostra indiferente, em princípio, questionando se aquilo que lhe acomete poderia ser tomado por vida. O enredo de $O$ Escafandro e a Borboleta (SCHNABEL, 2007) revela então um tom de moralidade que diz ser a vida uma necessidade de viver, enquanto se está respirando. Vários personagens no filme vêm até Dominique para lhe dizer que resista, que finque trincheira e lute por algum avanço em conjunto com as terapêuticas que lhe são endereçadas. Os esforços técnicos dos profissionais do hospital e de Dominique vão assumindo a cada cena um ar de comoção, como se o chão que Dominique perdera encontrasse solo fértil em cada coração que a sua narrativa possa vir a tocar.

Dominique é mais um caso que uma narrativa. Dominique é mais um exemplo que uma experiência posta a encontros. Dominique é uma realização através de seu olho esquerdo que aprende um modo de escrita para contar a sua própria história que, como história do indivíduo, pode ser a história de cada humano. Um acerto de contas. Entretanto, O Escafandro e a Borboleta (SCHNABEL, 2007) é um cinema de grande qualidade técnica e de fotografia inventiva. Faz do olho vivo de Dominique uma câmera privilegiada que captura o que se passa ao seu redor. Uma câmera precária que vê mal, que não foca bem e está sem referentes para entender o que se passa. Um médico lhe explica a situação. Parece pouco para Bauby, até que num breve passeio pela varanda do hospital o olho-câmera vê seu próprio corpo refletido numa parede espelhada. Daí a contra-partida em Dominique, que enxerga pela primeira vez e de maneira solitária, aquilo em que se transformou; um moribundo. É necessário cuidar do 
moribundo e é preciso que esse moribundo busque a superação da sua condição psico-fisiológica. É imperioso que Dominique se esforce para voltar à condição de conjunto, de ente de uma população produtiva.

Em O Escafandro e a Borboleta (SCHNABEL, 2007) as cenas se encaminham para avanços terapêuticos na vida de Dominique e, embalado pela bela trilha sonora de Charles Trenet - La Mer - Jean-Dominique Bauby vê a esperança fazendo-se chama para a sua existência. Sua tragédia ganha a circunstância do drama. O belo filme, a bela música e a inusitada condição de Dominique que entre o escafandro e a borboleta decide pela segunda, são ingredientes que despertam lágrimas silenciosas de muitos que o assistem, quando os créditos no fim da película começam a passar pela tela. A impressionante força de Bauby, quando disposta no modo-cinema, agrega pelo aperto ao coração, já que o chão de cada humano que o assiste, se renova com a esperança que Dominique não pode desfrutar. Morre de pneumonia logo após o lançamento de seu livro.

Em A Professora de Piano (HANEKE, 2001) a proposta segue outra direção. As cenas que atravessam a vida de Érika - personagem principal do filme encaminham mais desmanchamentos que edificações existenciais. As suas perdas não se configuram em danos. Érika é perfeccionista e não permite que paixões atravessem a sua atividade de intérprete e professora de piano. Disciplina, treinamento e apuro técnico orquestram-se naquilo que parece ser significado fundamental da existência de Érika. Mas a dedicação de Érika à música não é o tom exclusivo da sua vida. Érika experimenta passionalidades incomuns. Mora com a mãe e, numa cena, logo ao começo do filme, discute com ela e a agride fisicamente. Em seguida, as duas estão abraçadas, chorando e se desculpado. A rigidez disciplinar fracassa quando os afetos permitem um passeio à flor da pele (DOMINGUES, 2010). O fracasso da regularidade é ainda mais intenso quando Érika conhece um rapaz num recital, que tem grande talento para interpretações ao piano, mas que se nega a aprimorar esse talento através do esforço e da disciplina técnica. Entretanto, o rapaz apaixona-se por Érika e busca ter aulas com ela.

Um dia, numa audição de estudantes de piano, percebe que Érika enche de cacos de vidro os bolsos do casaco de uma aluna, que não quer ver apresentar-se. Covardemente inviabiliza a apresentação da garota e quando vai ao banheiro para se recompor é seguida pelo rapaz que, com indignação, lhe cospe a cara, para em seguida beijar-lhe a boca. Érika corresponde e vê ali seu chão de aparências sumir. Quer agora do rapaz esse amor dissonante, que mistura violência e gozo. Diz ao rapaz que quer o mesmo que ele, mas ele entende ser essa uma relação doentia e a abandona. Entretanto, não consegue se livrar de Érika e retorna a sua casa em busca de um encontro de termos, mas seu script não se realiza e ele estupra e espanca Érika. O imaginado subjaz ao inusitado. O filme se encaminha na tela e o final que seria marcado por um concerto tendo Érika como atração, se dá ainda no saguão do teatro quando ela encontra com um grupo de pessoas e dentre elas está o rapaz. Érika retira uma faca da bolsa e crava-a a altura da sua própria clavícula. 
Afasta-se das pessoas com a faca no corpo, saí do teatro e caminha pela noite. Assim encerra o filme A Professora de Piano (HANEKE, 2001). Érika é uma experiência em desacordo com as normas de convivência social. Érica é uma paixão que não consegue calar e não se permite domar, mesmo quando subjugada. Érika é o desterro voluntário da representação disciplinar. Antes perder o chão que aprisiona a perder a vida. Como quem inaugura um vôo com as pernas que possui. Estar em chão desconhecido é como que estar voando. A professora de piano é busca, é vontade, é invenção de vida, é a política de querer o mesmo que todo outro poderia querer, fazendo da própria existência uma obra de arte (FOUCAULT, 2004, 2000).

Os dois filmes não ensejam apenas dois mundos. Jean-Dominique Bauby em O Escafandro e a Borboleta (SCHNABEL, 2007) mira o mundo do íntimo, que se alimenta de esperança por renovações. Um mundo com lugares previstos e, quando muito, posto em reforma, para que o estranho, no íntimo de cada ser, não estranhe. A professora de piano pouco ensina além do rigor para o aprimoramento técnico do instrumento. Sua vida estranha a quem lhe assiste, porque se faz estranha a Érika. Há disposição em Érika e com isso os mundos vão se criando para além das teclas e sonoridades do seu piano.

Bauby instala um desconforto para em seguida confortar os corações apiedados. Érika retira o chão que pisa e apresenta mais perguntas que respostas. Escafandros e pianos. Professoras e borboletas. Películas que apertam o coração e que retiram o chão. Não se trata, aqui, de exercícios de análise dos filmes, mas sim uma consequente aproximação de um campo de estudos que investe em dispor sobre um modo outro de produzir olhares, tendo por princípio a política de intercessores proposta por Deleuze (1992). Desse modo se atenta para uma lógica filosófica problematizante em busca de encontros entre os precários vivos e inventivos.

\section{REFERÊNCIAS}

CONDE, H. B. Para desencaminhar o presente Psi: biografia, temporalidade e experiência em Michel Foucault. In: GUARESCHI, N.; HÜNING, S. (Org.). Foucault e a Psicologia. Porto Alegre: Abrapso SUL, 2005. p. 7-27.

DELEUZE, G. Conversações. Rio de Janeiro: Editora 34, 1992.

DOMINGUES, L. Aflor da pele: subjetividade, clínica e cinema no contemporâneo. Porto Alegre: Sulina, 2010.

O ESCAFANDRO e a borboleta. Direção de Julian Schnabel. Produção: Kathleen Kennedy e Jon Kilik. Roteiro: Ronald Harwood, baseado em livro de JeanDominique Bauby. EUA: Miramax Films; França: Europa Filmes, 2007. 1 DVD (112 min.).

FOUCAULT, M. Segurança, território, população. São Paulo: Martins Fontes, 2008. 
FOUCAULT, M. Ética, sexualidade, política. Rio de Janeiro: Forense Universitária, 2004. v. 5, Coleção Ditos e Escritos.

FOUCAULT, M. O que são as luzes? In: MOTTA, M. B. (Org.). Arqueologia das ciências e história dos sistemas de pensamento. Rio de Janeiro: Forense Universitária, 2000. v. 2, p. 335-351. Coleção Ditos e Escritos.

FOUCAULT, M. Em defesa da sociedade. São Paulo: Martins Fontes, 1999.

FOUCAULT, M. Vigiar e punir: história da violência nas prisões. Petrópolis: Vozes, 1995.

FOUCAULT, M. Microfisica do poder. Rio de Janeiro: Graal, 1993.

GUATTARI, F.; ROLNIK, S. Micropolíticas: cartografias do desejo. Petrópolis: Vozes, 1996.

HARDT, M. A sociedade mundial de controle. In: ALLIEZ, E. (Org.). Gilles Deleuze: uma vida filosófica. São Paulo: Editora 34, 2000.

KAFKA, F. A metamorfose. São Paulo: Brasiliense, 1986.

LATOUR, B. A esperança de Pandora: ensaios sobre a realidade dos estudos científicos. Bauru: Edusc, 2001.

MATURANA, H.; VARELA, F. A árvore do conhecimento. Campinas: Psi, 1995.

NEVES, C. A. B. Pensando o Contemporâneo no fio da navalha: entrelaces entre desejo e capital. Lugar comum, Rio de Janeiro, v.19/20, p.135-157, jan./jun. 2004.

NIETZSCHE, F. A genealogia da moral. Lisboa: Guimarães, 1976.

NIETZSCHE, F. Humano, demasiado humano. São Paulo: Companhia das Letras, 2000.

NIETZSCHE, F. Sabedoria para depois de amanhã. São Paulo: Martins Fontes, 2005.

APROFESSORAde Piano. Direção: Michael Haneke. Produção: Veit Heiduschka. Roteiro: Michael Haneke, baseado em livro de Elfriede Jelinek. França: Canal+; Les Films Alain Sarde; arte France Cinéma; MK2 Productions; Centre National de la Cinématographie; Eurimages; Áustria: Wega Film; Bayerischer Rundfunk; P.P. Film Polski; Österreichischer Rundfunk, 2001. 1 DVD (131 min.) 
VASCONCELLOS, J. Da imagem do pensamento e dos intercessores. In: VASCONCELlOS, J. (Org.). Deleuze e o Cinema. Rio de Janeiro: Ciência Moderna, 2006. p. 1-11.

VIRILIO, P. A máquina de visão. Rio de Janeiro: J. Olympio, 2002a.

VIRILIO, P. A arte do motor (1996). São Paulo: Estação Liberdade, 2002b.

Recebido em: 16 de julho de 2010 Aceito em: 13 de junho de 2011 